\title{
CONDUCTION IN THE AURICLES
}

\author{
BY A. E. NAISH
}

THE idea of a central conducting system of specialized neuro-muscular tissue leading right through from the sinus node to the termination of the Purkinje fibres in the ventricle would on a priori grounds seem probable, for in the early embryonic heart the auricular canal leads straight from the sinus to the ventricle, and the auricle is an outgrowth from this. So far histological evidence in favour of a specialized strand or strands of tissue connecting the sinus and Tawara nodes is unconvincing. Curran (2) and Thörel (6) have thought that they have found such connexions, but Aschoff (1), Mönckeberg (5), and Koch (4) have denied their existence. By means of their recent experimental investigations Eyster and Meek (3) have however obtained evidence in favour of the conduction of impulses between the two nodes taking place independently of the main body of the contracting auricular muscle. Testing dogs' hearts by the method of spread of electrical negativity, they have found that the excitation starts in the upper part of the sinus node, spreads rapidly throughout the node and to the neighbouring venous regions, but encounters resistance in its passage to the auricle across the sino-auricular junction, and in the great majority of cases reaches the Tawara node before it has spread to the body of the right auricle. In fourteen experiments the time taken in passing from the sinus node to the middle of the right auricle varied from 0.025 to 0.04 secs. Thus there is a definite $S-A s$ interval, occupying about quarter of the time of the $A s-V_{s}$ interval.

Clinical evidence in favour of or against a special path for conduction through the auricle is of necessity difficult to obtain, for there is no means of detecting the time of sinus excitation. Occasionally, however, tracings are difficult to explain on the supposition that conduction from the sinus to the ventricle takes place via the contracting auricular muscle, but become more intelligible if we suppose that the auricle is connected, so to speak, by a side chain to the conducting system, and that there is a definite $S-A s$ interval. That such an interval may be prolonged under pathological conditions seems very probable when we consider that dropped beats from sino-auricular block are a well-attested phenomenon.

The following case of acute heart-block accompanying typhoid fever and nephritis is brought forward as an example of the difficulty of explaining wholly 
the tracings on the hitherto accepted theory of conduction. A brief general account of the case is first given, and then the tracings are examined without regard to chronological order.

\section{Clinical Notes.}

George M., aged 18, admitted to the Sheffield Royal Hospital on March 13, 1913.

Owing to the fact that his mother was also suffering from typhoid at the same time, and that the patient himself was too ill to answer questions, no full history of his illness was obtained; but it was ascertained that he had been in bed at home for eight weeks.

He appeared very ill on admission, face pallid, lips cyanosed, temperature $103^{\circ} \mathrm{F}$., respirations 32 per minute, pulse 120 .

There was low delirium from time to time, but for the most part he lay quietly in bed without taking any notice of his surroundings. His bowels were constipated. The urine contained a large quantity of albumin and a little blood ; the specific gravity was 1.012 , and the quantity averaged over $1000 \mathrm{c.cm}$. per diem.

The blood gave a positive Widal reaction.

The heart showed some diffuse pulsation over the fourth and fifth left interspaces, but the apex beat was very indistinetly felt. The cardiac dullness extended from $1 \frac{1}{2}$ inches to the right to $4 \frac{3}{4}$ inches to the left of the mid-sternal line. The heart-sounds were very faintly heard, and unaccompanied by any murmurs.

There were dullness and crepitations at the bases of both lungs.

He remained in much the same condition for the next four days, the temperature varying between $100^{\circ}$ and $103^{\circ} \mathrm{F}$., and the pulse between 120 and 140 .

On March 17 the pulse fell to about 80 and became rather irregular, and at the same time the patient vomited, became very drowsy, and appeared almost moribund for a few hours.

During the next few days, though he vomited once or twice, his condition gradually improved; the urine contained decreasing quantities of albumin ; the temperature came down slowly, after the 27 th being seldom above normal; and the drowsiness diminished.

Between March 21 and April 1 the heart was nearly regular at the rate of about 50 per minute, and tracings showed that partial heart-block was present, the prevailing rhythm being $2: 1$. From April 1 onwards the normal $1: 1$ sequence became gradually more frequent and prolonged, though there were occasional relapses into $2: 1$ up to two weeks later.

Improvement continued, the albuminuria disappeared, and he was sent to a convalescent home on May 2.

\section{Polygraph Tracings.}

Fig. 1 is from a tracing taken on April 1, and is typical of what is seen over a considerable length of tracing taken on that day. It will be seen that sometimes the ventricular beats follow successive auricular beats, and that at other times the ventricle beats only once to every two auricular beats. Contrary to what one would expect, the $A s-V s$ intervals are not prolonged beyond the normal limit even in the beats immediately preceding the ventricular silences. This is quite exceptional; usually the interval is increased for a considerable time before 
the occurrence of dropped beats, though in some cases recorded the increase does not occur until the last few beats before the silence.

Further, it will be seen that the $A s-V_{s}$ intervals of the beats following the ventricular silences are very short, certainly not exceeding 0.08 of a second, and sometimes much less. It is hardly credible that the impulse has passed from auricle to ventricle in so short a time. These ventricular beats may of course be escapes, but considerably longer pauses between the first few idio-ventricular beats would be expected, especially after so fast a ventricular rate immediately preceding, for it is when suddenly deprived of rapid auricular impulses that the

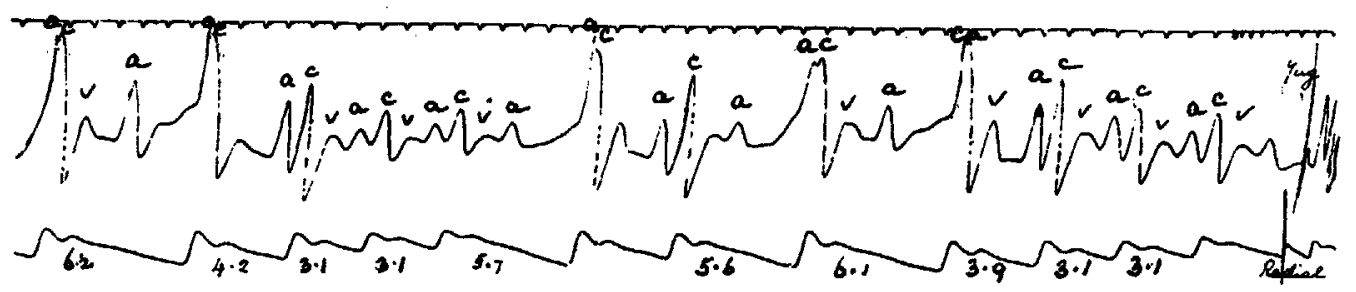

Fra. 1.

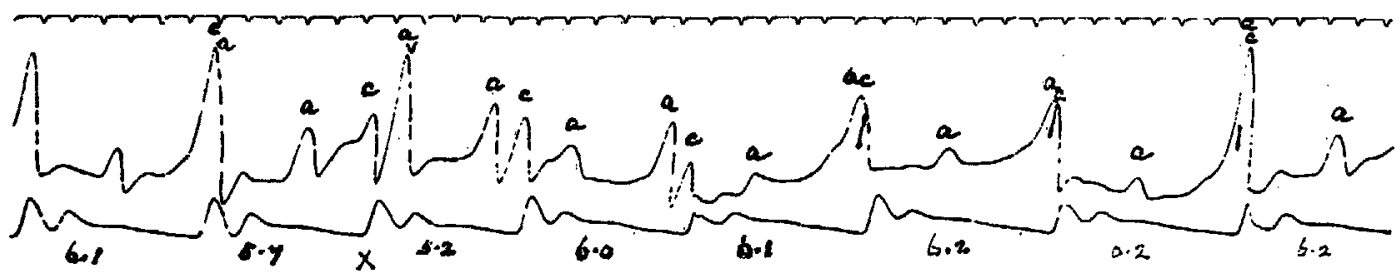

FIG. 2.

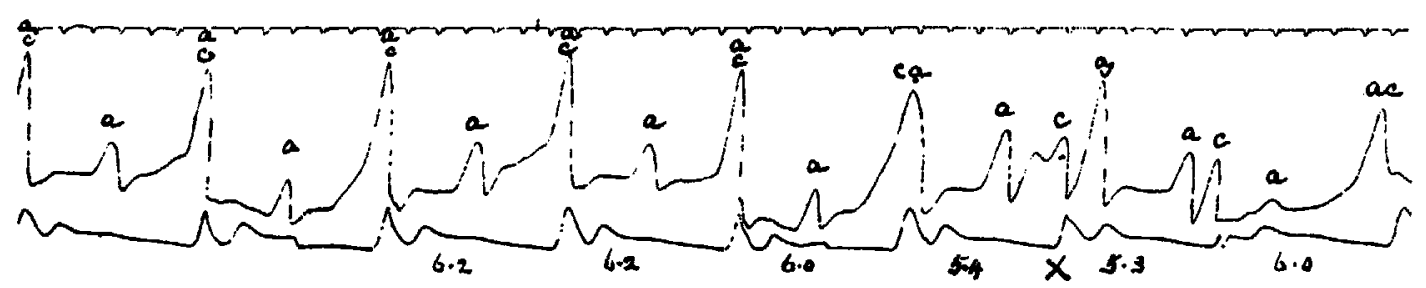

FIa. 3.

automatic action of the ventricle takes longest to develop. Further, this synchronism of $A$ and $V$ beats was a marked feature in tracings taken on every occasion on which any dissociation was present, although the auricular rate was by no means constant (see Fig. 3) and the repeated coincidence of the ventricular rate with a variable auricular rate would be very unlikely.

If on the otber hand we consider that the sinus excitation passes by separate paths to the auricle and ventricle, and that in this case the $S-A s$ interval is pathologically prolonged, the explanation of the tracing becomes quite simple. For instance, if the $S-A s$ intervals were 1 sec., the $S-V_{s}$ intervals before the dropped beats would be 0.3 sec., and those next after the dropped beats would be approximately $0 \cdot 16$ sec. 
Figs. 2 and 3 are the halves of a continuous piece of tracing. Many yards of tracing taken on March 29 and 30 were almost exactly of this type. Throughout these lengths of tracing, for a number of cycles varying from six to twenty-eight, the ventricular beat is almost precisely synchronous with every second auricular beat; then follow two shorter cycles in which the $c$ wave of the jugular pulse falls rapidly back nearer to the preceding $a$ wave, and following this for the next three or four cycles the $A s-V_{s}$ intervals gradually diminish till they are finally lost again.

How are we to explain this tracing? If we suppose that the ventricular beats following the shorter pauses are responses to the auricular impulses immediately preceding them, then in the succeeding cycles there is an extinction of the $A s-V_{s}$ interval.

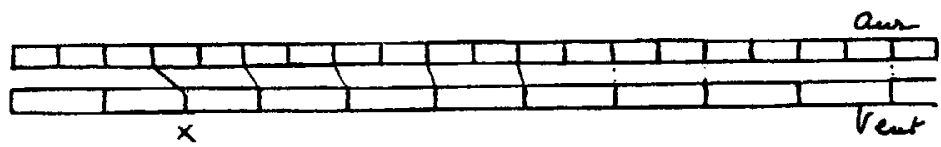

FIG. 4.

We may suppose that the ventricle begins to escape four or five cycles after the mark $\times$, but against this explanation are some of the facts mentioned above in commenting on Fig. 1. Further, during the five cycles in which the $a$ and $c$ waves do not fall together the $A s-V_{s}$ interval is getting progressively shorter, for which there seems to be no explanation.

Another possible explanation is that the synchronous ventricular beats are responses to the preceding auricular impulses.

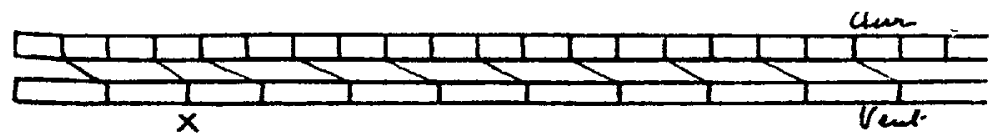

Frg. 5.

This would mean that the cycle immediately following the mark $x$ was a cycle of $1: 1$ rhythm, and that the ventricular beat at the end of this cycle was derived from an auricular impulse that had taken 4.2-fifths, or nearly half a second, to reach the ventricle, another auricular beat having actually been completed before the previous one had excited the ventricle. Such a sequence can hardly be considered likely, especially if this tracing be compared with that shown in Fig. 1, where a similar explanation would border on the absurd. (It must be remembered that other tracings show almost every gradation between the condition shown in Figs. 2 and 3 and that shown in Fig. 1 , so that the same explanation must probably apply to both.)

Adopting the supposition of a prolonged $S-A s$ interval and direct $S \cdot V$ conduction, the synchronous contraction of auricle and ventricle seen in Figs. 2 and 3 presents no difficulty, for the $S-V$ conducting path has had twice as long to rest as the $S-A$ path. On this supposition the cycle immediately preceding 
the mark $x$ is a $1: 1$ cycle, the $S-V$ interval lengthening out because of the short preceding pause.

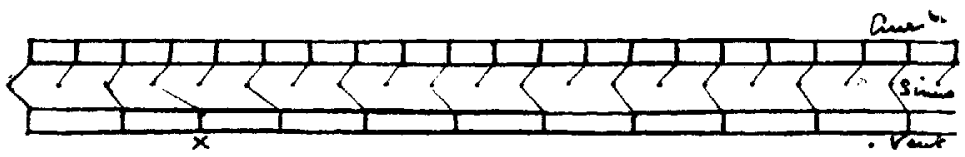

Fir. 6.

After this the $A s-V_{s}$ intervals progressively diminish, since the conduction path to the ventricle is gradually recovering from the exhaustion of having responded to two successive sinus excitations.

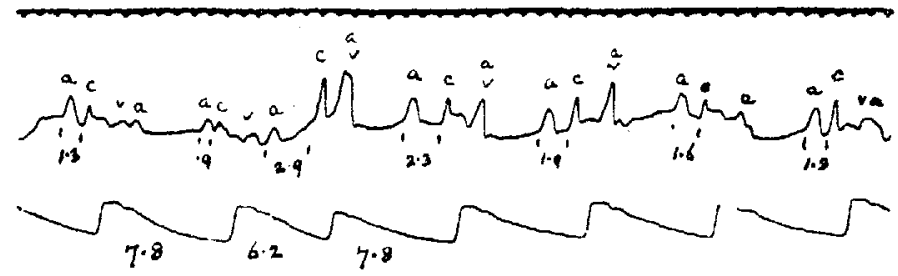

FIG. 7.

A similar progressive diminution of the $A s-V_{s}$ intervals after a single cycle of $1: 1$ rhythm is seen in Fig. 7, taken from another patient, in whom it was a frequently recurring phenomenon.

Summary.

Tracings are published from a cass of acute heart-block, which receive a ready explanation only upon the supposition that the cardiac impulse spreads to the ventricle and to the auricle by different paths, and does not pass to the ventricle through the auricle, as hitherto supposed.

In conclusion, my best thanks are due to my colleague Dr. Arthur J. Hall for his kind permission to examine and report on this case.

\section{BIBLIOGRAPHY.}

1. Aschoff, Centralbl. f. ally. Path. u. path. Anat., Jena, 1910, xxi. 433.

2. Curran, Anat. Anzeiger, Jena, 1909-10, xxxv. 89.

3. Eyster and Meek, Heart, Lond,, 1914, v. 119.

4. Koch, Archiv f. d. ges. Physiol., Bonn, 1913, cli. 279.

5. Mönckeburg, Centralbl. f. allg. Path. u. path. Anat., Jena, 1910, xxi. 437.

6. Thorel, Münch. med. Wochenschr., 1909, lvi. 2. 2159. 